
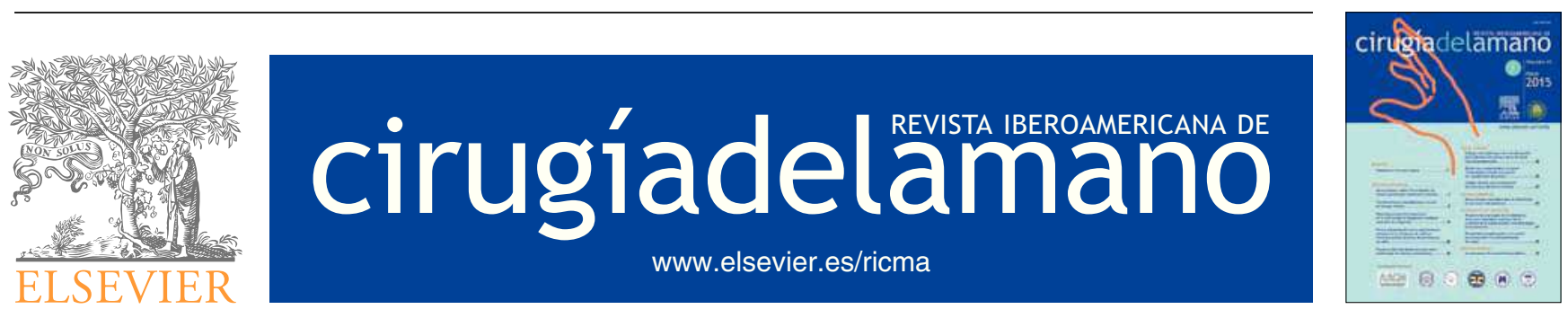

CASO CLÍNICO

\title{
Quiste óseo aneurismático en tercer metacarpiano tratado con injerto no vascularizado de peroné
} CrossMark

\author{
S. Losa*, F. Doñate y D. Gallach \\ Unidad de Tumores y Cirugía de la Mano, Cirugía Ortopédica y Traumatología, Complejo Hospitalario \\ Universitario de Albacete, Albacete, España
}

Recibido el 15 de diciembre de 2014. Aceptado el 31 de marzo de 2015.

\section{PALABRAS CLAVE \\ Quiste óseo aneurismático; Injerto no vascularizado de peroné; Resección}

\section{KEYWORDS}

Aneurysmal bone cyst; Non-vascularized fibular graft; Resection

\begin{abstract}
Resumen
Niño de 4 años que presenta un quiste óseo aneurismático de gran tamaño en tercer metacarpiano tratado mediante escisión radical e injerto no vascularizado de peroné.

( ) 2015, SECMA. Publicado por Elsevier España, S.L.U. Este es un artículo Open Acces distribuido bajo los términos de la licencia CC BY-NC-ND (http://creativecommons.org/licenses/by-nc-nd/4.0/).
\end{abstract}

Aneurysmal bone cyst in the third metacarpal treated

with a non-vascularized fibular graft

\begin{abstract}
A 4 year-old child with a giant aneurysmal bone cyst in the third metacarpal bone was treated with resection and reconstruction with a non-vascularized fibular graft.

( $)$ 2015, SECMA. Published by Elsevier España, S.L.U. This is an open access article under the CC BY-NC-ND license (http://creativecommons.org/licenses/by-nc-nd/4.0/).
\end{abstract}

\section{Introducción}

El quiste óseo aneurismático (QOA) es una lesión benigna o seudotumor óseo que se origina habitualmente en posición excéntrica de la metáfisis de huesos largos provocando abombamiento del hueso. Es una lesión poco frecuente, con una incidencia de 1,4 por millón de habitantes al año. Cons- tituye el $1 \%$ de los tumores óseos. Puede presentarse a cualquier edad aunque es más frecuente en las dos primeras décadas de la vida.

En cuanto a la localización, es típico de la metáfisis de huesos largos, habitualmente en posición excéntrica. En orden decreciente se localiza en huesos largos de extremidad inferior, en huesos largos de extremidad superior, esqueleto

*Autor para correspondencia.

Correo electrónico: sergiolosapalacios@gmail.com (S. Losa).

( ) 2015, SECMA. Publicado por Elsevier España, S.L.U. Este es un artículo Open Acces distribuido bajo los términos de la licencia CC BY-NC-ND (http://creativecommons.org/licenses/by-nc-nd/4.0/). 
axial y en huesos planos. La localización en zonas acras es infrecuente y presenta una incidencia en las manos entre el 3 y el $4,7 \%$.

El estudio radiológico simple es característico, observándose una lesión lítica, con abombamiento y en ocasiones con tabiques internos que dan un aspecto en pompas de jabón. Sin embargo, la resonancia magnética es más útil para realizar el diagnóstico diferencial, presentando contenido líquido que se realza en T2 en forma de niveles y se atenúa en $\mathrm{T} 1{ }^{2}$.

La teoría etiopatogénica más difundida es la de un proceso reactivo a una malformación venosa, aunque se ha descubierto una translocación $\mathrm{t}(16 ; 17)$ (q22;p13) recurrente en QOA primarios ${ }^{3}$.

Su biopsia es necesaria, ya que se puede confundir con lesiones malignas ${ }^{1}$. Existen varias alternativas terapéuticas, algunas de ellas poco agresivas al tratarse de una lesión benigna.

A continuación se presenta un caso de QOA que recidiva hasta en tres ocasiones, precisando una escisión radical finalmente.

\section{Caso clínico}

Niño de 4 años de edad que acude a consulta con una tumo-

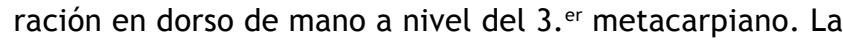
lesión no es dolorosa a la palpación y la movilidad de muñeca y dedos es normal.

En la radiografía simple se observa insuflación de corticales con rotura de la misma (fig. 1A). Ante la sospecha clínica de encondroma y dado el tamaño del mismo se decide realizar legrado y relleno con hidroxiapatita (fig. 1B). Se envía muestra al Servicio de Anatomía Patológica y se diagnostica de quiste óseo aneurismático.

Un año más tarde la tumoración recidiva (fig. 2A) y radiológicamente aparecen signos compatible con QOA (fig. 2B), ya diagnosticado por la biopsia previa, por lo que se decide realizar una embolización (fig. 3) por parte del servicio de
Radiología Intervencionista. No da resultado esta primera embolización por lo que se realiza una segunda embolización, que tampoco es efectiva.

Ante el resultado negativo del tratamiento con embolizaciones se decide realizar una escisión radical de la tumoración respetando las fisis y aportando injerto óseo no vascularizado de peroné autólogo, la edad del paciente en ese momento era de 7 años. La fijación del injerto se realiza mediante una aguja de Kirschner axial (figs. 4A y 4B).

A los 6 meses de la cirugía, el paciente está realizando vida normal y radiográficamente se observa integración del injerto, pero sin signos de remodelación ósea (fig. 5A). Al año de la cirugía presenta una movilidad metacarpo-falángica completa con un déficit de extensión de $5^{\circ}$. Radiográficamente se observa la remodelación ósea y la integración del injerto (fig. 5B).

7 años más tarde la función de la mano es completamente normal. Se observa cierre de las fisis lo que determinará una menor longitud del metacarpiano. Presenta una deformidad del tobillo donante en valgo (ángulo tibio-astragalino de $69^{\circ}$ frente a los $94^{\circ}$ del contralateral) por lo que se le realiza una hemiepifisiodesis de tibia distal con placa en 8 , más un tornillo suprasindesmal. Un año más tarde se realiza retirada del implante con una corrección casi completa de la deformidad (ángulo tibio-astragalino de $83^{\circ}$ ).

\section{Discusión}

El QOA es característico de las metáfisis de huesos largos, siendo infrecuente su localización en la mano (3-4,7\%), con no más de 13 casos publicados en la literatura ${ }^{4}$. En el caso presentado, llama la atención el gran tamaño de la lesión, ya que ocupa toda la diáfisis y la metáfisis del metacarpiano. Su comportamiento es localmente agresivo, deformando los metacarpianos vecinos.

Radiográficamente, a veces resulta imposible distinguirlos de los tumores de células gigantes o de los encondromas. En


Figura 1 (A) Imagen lítica que ocupa la totalidad del tercer metacarpiano, abomba y rompe corticales y se intuye alguna calcificación en el interior. (B) Radiografía postoperatoria tras legrado y relleno con hidroxiapatita.

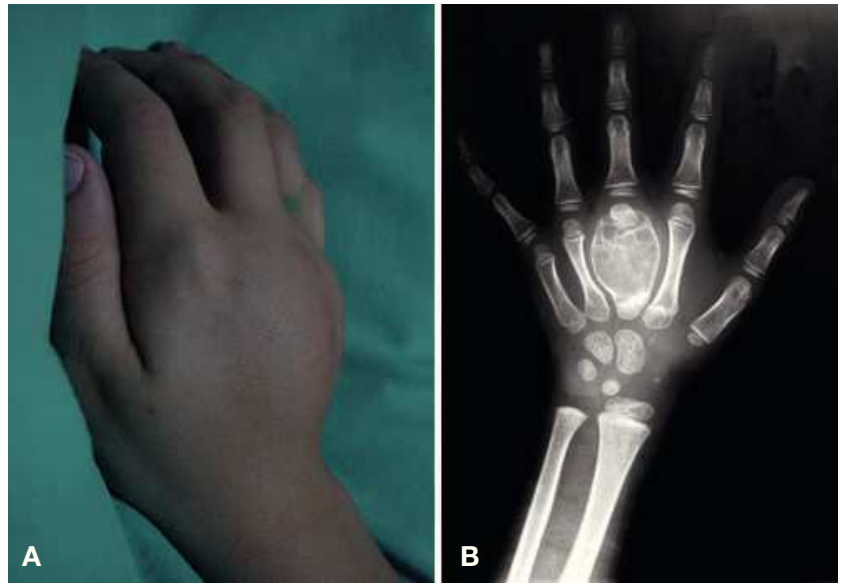

Figura 2 (A) Recidiva de la tumoración que ocupa el dorso de la mano. (B) Radiografía en la que se observan imágenes en "pompa de jabón" y deformidad de los metacarpianos vecinos. 


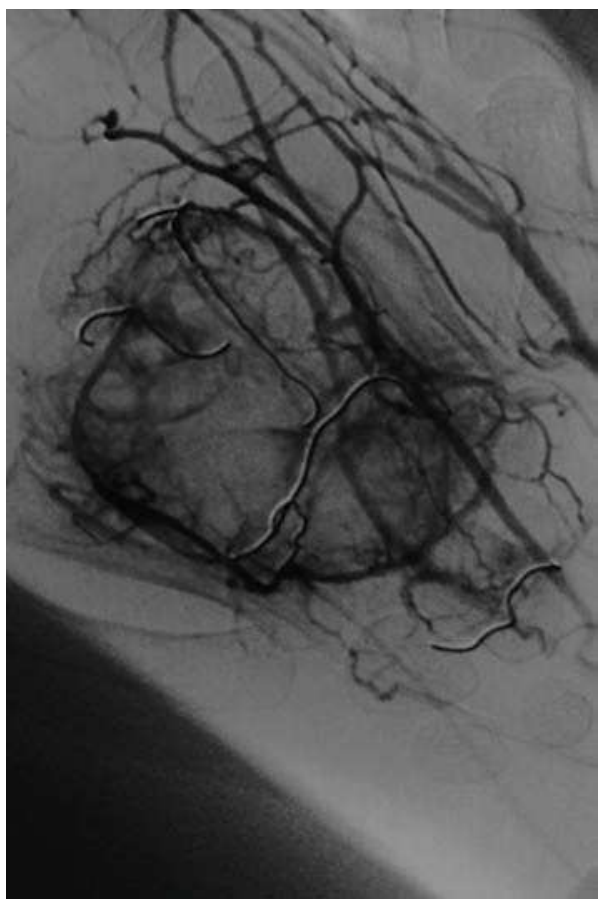

Figura 3 Imagen de arteriografía en la que se realiza embolización mediante coils metálicos de los múltiples vasos que irrigan la tumoración.

nuestro caso el diagnóstico clínico inicial fue de encondroma, pero la anatomía confirmó la existencia de QOA. Dentro del diagnóstico diferencial se encuentran: el quiste óseo simple, granuloma eosinófilo, fibroma no osificante, displasia fibrosa, fibroma condromixoide, tumor células gigantes, encondroma y el osteosarcoma telangiectásico. Se han descrito casos de transformación maligna incluso años después del legrado del quiste.



Figura 4 (A) Radiografía postoperatoria en la que se observa el injerto de peroné sintetizado con una aguja de Kirschner. También se observan los coils metálicos utilizados en las embolizaciones previas. (B) Imagen intraoperatoria del injerto de peroné.



Figura 5 (A) Radiografía a los 6 meses donde se observa la integración del injerto. (B) Integración del injerto con remodelación del tercer metacarpiano que muestra un aspecto similar a los metacarpianos vecinos. Se observa cierre de las fisis lo que determinará una menor longitud del metacarpiano. En amas imágenes se observan los coils metálicos de las embolizaciones previas.

El legrado y relleno de la cavidad presenta una recidiva del 0-30,8\%1. El único tratamiento curativo es la resección amplia. Hay descritos otros tratamientos menos agresivos como la radioterapia, la inyección de prolamina, la crioterapia e inyecciones percutáneas de matriz ósea desmineralizada asociada a médula ósea, calcitonina y metilprednisolona, sulfato de calcio, escleroterapia con polidocanol ${ }^{1}$.

En nuestro caso ante la recidiva tras el legrado y relleno con hidroxiapatita optamos por realizar una embolización selectiva, con la que De Cristofaro y cols. ${ }^{6}$ presentan una curación de hasta el $89 \%$.

Pino-Almero y cols. ${ }^{5}$ describen un caso de QOA subperióstico en un quinto metatarsiano del pie, tratado mediante resección del quiste y con una evolución favorable del mismo sin datos de recidiva tras dos años de seguimiento.

Abuhassan y cols. ${ }^{7}$ describen 3 casos de QOA gigante en los que realizan una resección y reconstrucción con injerto no vascularizado de peroné. Uno de ellos corresponde a la zona metafisaria proximal de fémur, otro a la diáfisis de húmero y el tercero corresponde a un niño de 8 años con un QOA que engloba todo el tercer metatarsiano. En el caso presentado se produjo la integración del injerto y en la evolución podemos observar la remodelación ósea adaptando el injerto la forma de metacarpiano. También observamos como se corrige la deformidad de los metacarpianos vecinos.

Vista la evolución posterior, creemos que es necesario colocar un tornillo suprasindesmal en la zona dadora del injerto de peroné para evitar la deformidad en valgo del tobillo y evitar una cirugía correctora posteriormente.

La resección en bloque y la reconstrucción con injerto no vascularizado de peroné puede ser una alternativa más de tratamiento para QOA de gran tamaño y rebeldes a tratamientos menos agresivos. 


\section{Agradecimientos}

Agradecemos al Dr. Indalecio Gracia su entusiasmo y sus enseñanzas en Cirugía de la Mano.

\section{Conflicto de intereses}

Los autores declaran no tener ningún conflicto de intereses.

\section{Bibliografía}

1. Docquier PL, Glorion C, Dolloye $C$. Kyste osseus anèvrismal. EMC Appareil locomoteur. Paris: Elsevier Masson; 2011. p. 771.

2. Sullivan RJ, Meyer JS, Dormans JP, Davidson RS. Diagnosing aneurysmal and unicameral bone cysts with magnetic resonance imaging. Clin Orthop Relat Res. 1999;366:186-90.
3. Panoutsakopoulos G, Pandis N, Kyriazoglou I, Gustafson P, Mertens F, Mandahl N. Recurrent t(16;17)(q22;p13) in aneurysmal bone cysts. Genes Chromosomes Cancer. 1999;26:265-6.

4. Tarazona-Velutini P, Romo-Rodríguez R, Saleme-Cruz J. Quiste óseo aneurismático en falange proximal de dedo de mano. Caso clínico y revisión de la bibliografía. Acta Ortop Mex. 2012;26: 245-9.

5. Pino-Almero L, Mínguez-Rey MF, Faus-Alcañiz MC. Quiste óseo aneurismático subperióstico localizado en quinto metatarsiano en una niña de 13 años: a propósito de un caso. Rev Esp Cir Ortop Traumatol. 2010;54:310-3.

6. De Cristofaro R, Biagini R, Boriani S, Ricci S, Ruggieri P, Rossi G, et al. Selective arterial embolization in the treatment of aneurysmal bone cyst and angioma of bone. Skeletal Radiol. 1992;21: 523-7.

7. Abuhassan FO, Shannak A. Non-vascularized fibular graft reconstruction after resection of giant aneurysmal bone cyst (ABC). Strateg Trauma Limb Reconstr. 2010;5:149-54. 